\title{
Regulation of Kinetic Properties of GluR2 AMPA Receptor Channels by Alternative Splicing
}

\author{
Maki Koike,, ${ }^{1,2}$ Shota Tsukada, ${ }^{1}$ Keisuke Tsuzuki, ${ }^{1,2}$ Hiromasa Kijima, ${ }^{3}$ and Seiji Ozawa ${ }^{1,2}$ \\ ${ }^{1}$ Department of Physiology, Gunma University School of Medicine, Maebashi, Gunma 371-8511, Japan, ${ }^{2}$ Core Research \\ for Evolutional Science and Technology, Japan Science and Technology Corporation, Kawaguchi, Saitama 332-0012, \\ Japan, and ${ }^{3}$ Department of Physics, Graduate School of Science, Nagoya University, Nagoya 464-8602, Japan
}

The four subunits of the AMPA-type glutamate receptor (GluR1-GluR4 or GluR-A-GluR-D) exist in two distinct forms, flip and flop, generated by alternative splicing of a $115 \mathrm{bp}$ region. The GluR2 subunit plays a key role in determining the functional properties of the AMPA receptor channel. In this study, we examined the differences in kinetic properties between the flip and flop splice variants of the GluR2 subunit expressed in Xenopus oocytes using fast agonist application techniques. Glutamate was applied to outside-out patches from oocytes with piezo-driven double-barreled application pipettes. Because homomeric receptor channels composed of the edited form of GluR2 (GluR2R) produce no appreciable current responses, we expressed the unedited form of GluR2 (GluR2Q) in oocytes, which produced large current responses sufficient for analysis of the kinetic properties. The time con-

AMPA receptor channels (AMPARs) mediate fast excitatory neurotransmission in most of the synapses in the CNS. Four cDNA clones of AMPA receptor subunits GluR1-GluR4 (GluRA-GluR-D) have been isolated by molecular cloning (Hollmann et al., 1989; Boulter et al., 1990; Keinänen et al., 1990). The GluR2 subunit plays a key role in determining the functional properties of AMPAR, such as rectification properties and $\mathrm{Ca}^{2+}$ permeability (Hollmann et al., 1991; Bochet et al., 1994; Jonas et al., 1994). Receptors with GluR2 exhibit either linear or outwardly rectifying current-voltage $(I-V)$ relationships and little $\mathrm{Ca}^{2+}$ permeability, whereas those without GluR2 show inward rectification and high $\mathrm{Ca}^{2+}$ permeability. The unique role of GluR2 has been traced to a single amino acid residue in the second hydrophobic region (M2). This residue is an arginine (R) in GluR2, whereas it is a glutamine (Q) in the other subunits. This site has been referred to as the Q/R site (Hume et al., 1991; Verdoorn et al., 1991; Seeburg, 1993; Hollmann and Heinemann, 1994). When the arginine in this site is replaced with glutamine, the receptor shows marked inward rectification and high $\mathrm{Ca}^{2+}$ permeability. Sommer et al. (1991) have demonstrated that the arginine in the $\mathrm{Q} / \mathrm{R}$ site is not encoded on the GluR2 genomic DNA but introduced by RNA editing to replace the geneencoded glutamine. This RNA editing is developmentally regu-

Received Oct. 29, 1999; revised Jan. 3, 2000; accepted Jan. 5, 2000.

This work was supported by the Japan Science and Technology Corporation and Research Fellowships from the Japan Society for the Promotion of Science for Young Scientists.

Correspondence should be addressed to Maki Koike, Department of Physiology, Gunma University School of Medicine, 3-39-22 Showa-machi Maebashi, Gunma, 371-8511 Japan. E-mail: mkoike@sb.gunma-u.ac.jp.

Copyright (C) 2000 Society for Neuroscience $0270-6474 / 00 / 202166-09 \$ 15.00 / 0$ stant for desensitization during application of $1 \mathrm{~mm}$ glutamate was $5.89 \pm 0.17 \mathrm{msec}(n=50)$ in flip and $1.18 \pm 0.05 \mathrm{msec}$ $(n=37)$ in flop. The deactivation time constant was $0.62 \pm 0.06$ msec $(n=10)$ in flip and $0.54 \pm 0.05 \mathrm{msec}(n=10)$ in flop. The steady-state nondesensitizing current was $6.8 \pm 0.4 \%(n=53)$ of the peak current in flip, whereas it was almost negligible in flop, being only $1.1 \pm 0.1 \%(n=36)$. The slower desensitization kinetics and larger steady-state current responses in the flip variant were also observed in heteromeric receptors assembled from GluR2Q/GluR2R. Thus, desensitization occurred much more prominently in the flop variant in the recombinant GluR2 receptor channels.

Key words: AMPA receptor channel; GluR2; flip/flop splice variants; $Q / R$ site; desensitization; deactivation lated. In embryos, a small percentage of the GluR2 is not edited, and therefore the unedited form (GluR2Q) coexists with the edited form (GluR2R). Postnatally, however, virtually all GluR2 exists in the edited form (Sommer et al., 1991; Burnashev et al., 1992).

The molecular diversity of AMPAR subunits is further increased by the presence of splicing variants. Each of GluR1GluR4 exists in two different forms, flip and flop, generated by alternative splicing of a 115 bp region immediately preceding M4 (Sommer et al., 1990; Monyer et al., 1991). Using a fast perfusion technique in outside-out membrane patches of Xenopus oocytes expressing recombinant AMPA receptor subunits, Mosbacher et al. (1994) have shown that, among homomeric GluR1, GluR3, and GluR4 receptors, the GluR4 flop receptor shows the fastest desensitization time constant, $0.9 \mathrm{msec}$, and the GluR3 flip receptor the slowest, $4.8 \mathrm{msec}$, when $1 \mathrm{~mm}$ glutamate is applied rapidly. The desensitization kinetics of homomeric GluR2, however, have not been investigated, because the homomeric receptor composed of the edited form of GluR2 does not generate sufficiently large current responses to allow detailed analysis of the channel-gating kinetics. In this study, we examined differences in the kinetics of desensitization and deactivation between flip and flop in homomeric GluR2Q and heteromeric GluR2Q/GluR2R receptors expressed in Xenopus oocytes, from which appreciable current responses could be recorded in the outside-out patch configuration.

\section{MATERIALS AND METHODS}

Plasmids and mutagenesis. GluR2Q cDNA was produced by site-directed mutagenesis (Sculptor IVM; Amersham, Buckinghamshire, UK) that exchanged $\mathrm{G}$ at position 1820 of the GluR2 flip to A. This point mutation 
changed arginine (R) at the $\mathrm{Q} / \mathrm{R}$ site to glutamine (Q). GluR2Q flop cDNA used in this study was synthesized from GluR2Q flip cDNA by replacing the Bam-XhoI fragment (nucleotide 2278-3300 that contains the flip-flop site) with the corresponding portion of the wild-type GluR2 flop cDNA. The rat wild-type GluR2 flip and GluR2 flop cDNAs were kind gifts from Drs. Jim Boulter, Stephan F. Heinemann, and Michael Hollmann (Salk Institute, La Jolla, CA). It has been shown that kinetic properties of recombinant AMPARs are affected by RNA editing. In the GluR2 subunit, a codon switch from AGA (arginine) to GGA (glycine) in the primary transcript is determined by intronic elements at a position termed the $\mathrm{R} / \mathrm{G}$ site that immediately precedes the flip-flop site (Lomeli et al., 1994). In this study, we used the edited form in which the $R / G$ site is occupied by $\mathrm{G}$ (glycine) for both flip and flop variants. $\mathrm{G}$ form, the edited form, is predominant in both flip and flop variants of the GluR2 subunit in the adult brain (Lomeli et al., 1994).

Expression of cDNAs. Capped cRNAs for GluR2Q and GluR2R were transcribed with T3 RNA polymerase in vitro from linearized plasmids (MEGAscript T3 kit; Ambion, Austin, TX). GluR2Q cRNA ( $\sim 50 \mathrm{ng} /$ oocyte) was injected into oocytes of Xenopus laevis. After incubation for $1-2 \mathrm{~d}$ in modified Barth's medium containing (in $\mathrm{mm}$ ) $88 \mathrm{NaCl}, 1 \mathrm{KCl}$, $2.4 \mathrm{NaHCO}_{3}, 0.3 \mathrm{Ca}\left(\mathrm{NO}_{3}\right)_{2}, 0.4 \mathrm{CaCl}_{2}, 0.8 \mathrm{MgSO}_{4}$, and $15 \mathrm{HEPES}$, titrated to $\mathrm{pH} 7.6$ with $\mathrm{NaOH}$, at $17^{\circ} \mathrm{C}$, oocytes were treated with $1 \mathrm{mg} / \mathrm{ml}$ collagenase (Yakult, Tokyo, Japan) for 15-30 min, and the follicular cell layers were removed. Electrophysiological recordings were performed at room temperature $\left(20-24^{\circ} \mathrm{C}\right) 4-8 \mathrm{~d}$ after treatment with collagenase.

Outside-out patch recording. The normal Ringer's solution (control solution) for current measurements contained (in mM): $112 \mathrm{NaCl}, 2 \mathrm{KCl}$, $2 \mathrm{CaCl}_{2}$, and 10 HEPES, titrated to $\mathrm{pH} 7.4$ with $\mathrm{NaOH}$. Patch pipettes were pulled from standard-wall borosilicate glass (GC150F-15; Clark Electromedical Instruments, Pangbourne, UK). The internal solution contained (in mM): $80 \mathrm{KF}, 20 \mathrm{KCl}, 10 \mathrm{~K}$-EGTA, and $10 \mathrm{HEPES}, \mathrm{pH}$ adjusted to 7.2 with $\mathrm{KOH}$. To maintain rectification properties of the AMPAR in the outside-out patch configuration, $100 \mu \mathrm{M}$ spermine was added to the internal solution (Bowie and Mayer, 1995; Donevan and Rogawski, 1995; Isa et al., 1995; Kamboj et al., 1995; Koh et al., 1995). In some experiments, $2 \mathrm{~mm} \mathrm{Mg} \mathrm{Mg}_{2}$ TP and $0.2 \mathrm{mM} \mathrm{Na}_{3}$ GTP were added to the internal solution. The pipettes had a resistance of 3-5 $\mathrm{M} \Omega$ when filled with the internal solution. For recording in the outside-out patch mode, the vitelline envelopes were removed with forceps after immersing the oocytes in hypertonic Ringer's solution for several minutes. All recordings were made using an EPC-7 patch-clamp amplifier (List Electronics, Darmstadt, Germany). Current traces were filtered at $3 \mathrm{kHz}$ with an eight-pole low-pass Bessel filter, digitized at 10-250 $\mu \mathrm{sec} /$ point, and stored on computer. The pClamp system (Axon instruments, Foster City, CA) was used for data acquisition and analysis.

Fast application of agonists. The experimental arrangement for the fast application of agonists is illustrated in Figure $1 A$. Double-barreled application pipettes were fabricated from theta glass tubes $(2.0 \mathrm{~mm}$ outer diameter, TGC200-15; Clark Electromedical Instruments) pulled out to a tip diameter of $\sim 200-300 \mu \mathrm{m}$. Control solution (normal Ringer's solution) and test solution (solution containing agonist) was passed continuously through each barrel of the theta glass tube under static pressure. The tip of the patch pipette was positioned close to the interface between the two solutions. To make a clear interface between the stream of the two solutions, $10 \mathrm{~mm}$ sucrose was added. The application pipette was operated by a piezoelectric device (PZ-150M; Burleigh Instruments, Fishers, NY) to achieve fast translocation of the interface. The time required for solution exchange was estimated by measuring open tip responses for junction potential between normal Ringer's solution and 10\% normal Ringer's solution (Colquhoun et al., 1992). An example of open tip response to a $1 \mathrm{msec}$ solution change is shown in the inset of Figure $1 \mathrm{~A}$. The $20-80 \%$ rise time ranged from 50 to $150 \mu \mathrm{sec}$. Agonist pulses were applied to outside-out patches every 3-5 sec. To induce current responses of AMPARs, L-glutamate or kainate (Wako, Osaka, Japan) was applied at various concentrations. The agonist barrel of the application pipette was connected to three reservoirs containing different drug solutions through miniature solenoid valves so that responses to the three different drugs could be tested in the same outsideout membrane patch. Time required for complete exchange to new drug solution was $\sim 20 \mathrm{sec}$. Cyclothiazide (CTZ) (Tocris Cookson, Bristol, UK) was dissolved in DMSO and diluted with normal Ringer's solution. The final DMSO concentration was $0.1 \%$.

Kinetic model. To predict current responses of outside-out patches to fast application of glutamate, we adopted a kinetic model assuming two

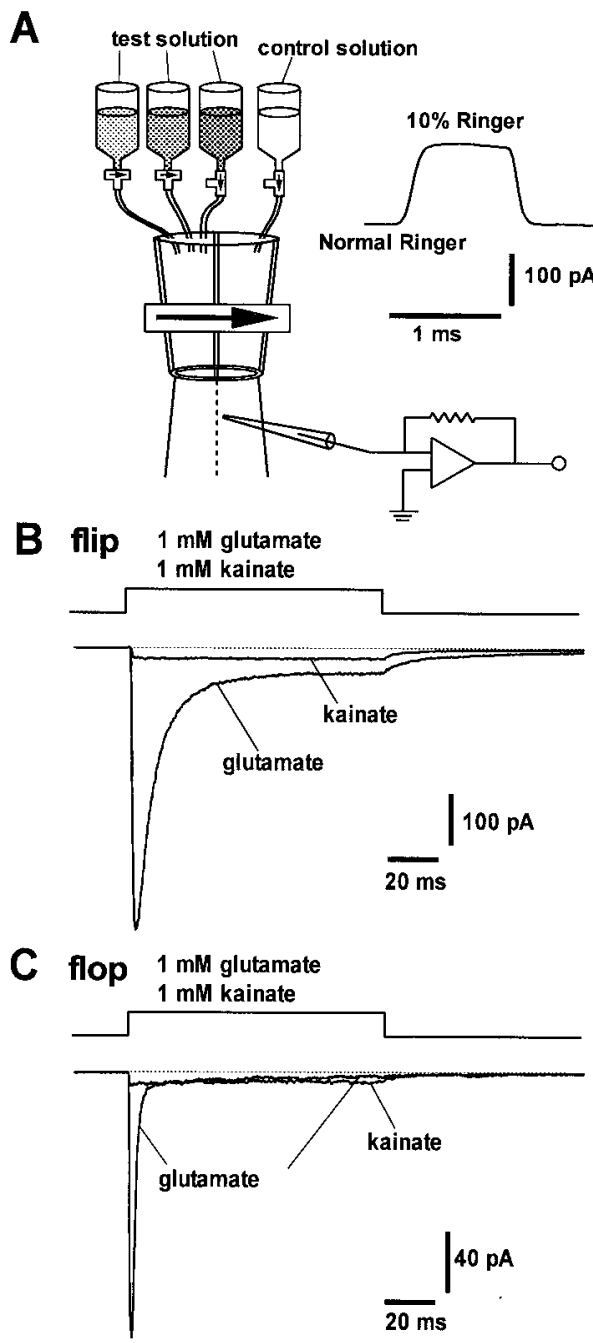

Figure 1. Current responses of homomeric GluR2Q AMPA receptor channels in outside-out patches to fast application of glutamate and kainate. $A$, Schematic drawing of fast application of agonist to excised outside-out patch with a piezo-driven double-barreled application pipette. Inset shows an open tip response caused by a $1 \mathrm{msec}$ solution change between normal Ringer's solution and $10 \%$ normal Ringer's solution. $B$, $C$, Currents evoked by $100 \mathrm{msec}$ pulses of $1 \mathrm{~mm}$ glutamate and $1 \mathrm{~mm}$ kainate in outside-out membrane patches excised from oocytes injected with cRNAs of flip $(B)$ and flop $(C)$ variants of the unedited form of GluR2 (GluR2Q). Glutamate and kainate responses were obtained from the same patch. Duration of agonist application is indicated by the rectangular pulse at the top of the current traces. Membrane potential was held at $-100 \mathrm{mV}$.

binding sites of the agonist on a channel and desensitization of the agonist-bound channel before and after opening of the channel (Dudel et al., 1990, Jonas et al., 1993) (see Fig. 5A). Rate constants in the model were obtained using a combination of trial and error and optimization, as described by Häusser and Roth (1997), but with some modifications. Briefly, starting from the initial values of the rate constants selected arbitrarily, a model-predicted current trace was obtained by digitally solving a set of differential rate equations with $50 \mu \mathrm{sec}$ time intervals using the fourth-order Runge-Kutta method with Excel (Office 97; Microsoft, Seattle, WA) running on an IBM personal computer. The rate constants were changed by trial and error to minimize the differences between the experimental and model-predicted current traces. We then adopted nonlinear least-square method for further automatic minimization. For example, to fit the desensitization time course, we minimized the sum of the square differences between the experimental currents and the predicted ones during the desensitization, putting a partial set of rate constants greatly affecting desensitization as free variables, subject to the 
condition of microscopic reversibility. This minimization of the square sum was performed with Solver in Excel with the termination criteria of $<10^{-10}$ relative errors of each rate constant in the successive minimization trials.

Analysis. To estimate the open probability at the peak of the current response to glutamate, we performed nonstationary fluctuation analysis (Sigworth, 1980). Transient responses to step applications of 1 or $10 \mathrm{~mm}$ glutamate were stored on a computer disk. The mean current and variance for each sample point were calculated across 20-40 current traces. The value of the baseline variance was subtracted from the variance calculated above. The value of the variance $\left(\sigma^{2}\right)$ thus obtained was plotted against the mean current $(I)$. The resulting plot was fitted with the function: $\sigma^{2}=i I-I^{2} / N$, where $i$ is the single-channel current, and $N$ is the number of available channels in the patch. The open probability of channels at the peak of the current was obtained by dividing the amplitude of the peak current by $i N$.

All data are expressed as means \pm SEM. Statistical analysis was performed using Student's two-sided $t$ tests, and differences were considered significant at $p<0.05$.

\section{RESULTS}

\section{Responses to glutamate and kainate in flip and flop splice variants}

Fast application of $1 \mathrm{~mm}$ glutamate for $100 \mathrm{msec}$ to outside-out patches excised from Xenopus oocytes expressing either flip or flop variant of GluR2Q produced current responses that rose rapidly to a peak and then showed marked desensitization (Fig. $1 B, C)$. The membrane potential was held at $-100 \mathrm{mV}$ throughout this study. The $20-80 \%$ rise time was much faster in flop $(0.28 \pm 0.01 \mathrm{msec}, n=36)$ than in flip $(0.53 \pm 0.03 \mathrm{msec}, n=32)$. The desensitization time constant was also much faster in flop than in flip (see below). The response in flip displayed an appreciable current at steady state, and the ratio of the amplitude of the steady-state current measured immediately before cessation of the glutamate pulse to that of the peak current was $6.8 \pm 0.4 \%$ $(n=53)$. In contrast, the steady-state current in flop was almost negligible, being only $1.1 \pm 0.1 \%(n=36)$ of the peak current.

Kainate at $1 \mathrm{~mm}$ produced nondesensitizing currents in both variants. The amplitude of the kainate response was smaller than that of the steady-state current response to glutamate in flip $\left(I_{\mathrm{KA}} / I_{\mathrm{Glu}}=0.39 \pm 0.04, n=5\right)$, whereas the opposite was true in flop $\left(I_{\mathrm{KA}} / I_{\mathrm{Glu}}=3.56 \pm 1.13, n=5\right)$.

\section{Dose-response relationship}

Figure 2 shows dose-response relationships for the responses to glutamate in both flip and flop variants. The peak amplitude of the response to $1 \mathrm{~mm}$ glutamate was taken as a reference, and the response ratio, i.e., the peak amplitude of the response at various glutamate concentrations divided by that at $1 \mathrm{~mm}$ glutamate, was plotted against the log of glutamate concentration. The doseresponse curve that fits the data best predicts a half-maximal response at $1.39 \mathrm{~mm}$ and a Hill coefficient of 1.08 in flip. The corresponding values in flop, $1.38 \mathrm{~mm}$ and 1.10 , were similar to those in flip (Fig. 2). These results suggested that flip-flop splicing does not affect the binding affinity of glutamate to AMPARs.

\section{Kinetics of desensitization and deactivation}

Figure 3 shows responses to $100 \mathrm{msec}$ glutamate pulses at various concentrations in flip and flop. With increasing concentrations, both activation and desensitization kinetics became faster, although the kinetics were much faster in flop than in flip at all concentrations examined (Fig. $3 A, B$ ). The desensitization time constant was obtained by fitting the current decay between 90 and $10 \%$ of the peak amplitude of the response with a single exponential function. When the amplitude of the steady-state current was larger than $10 \%$ of the peak, fitting was performed between
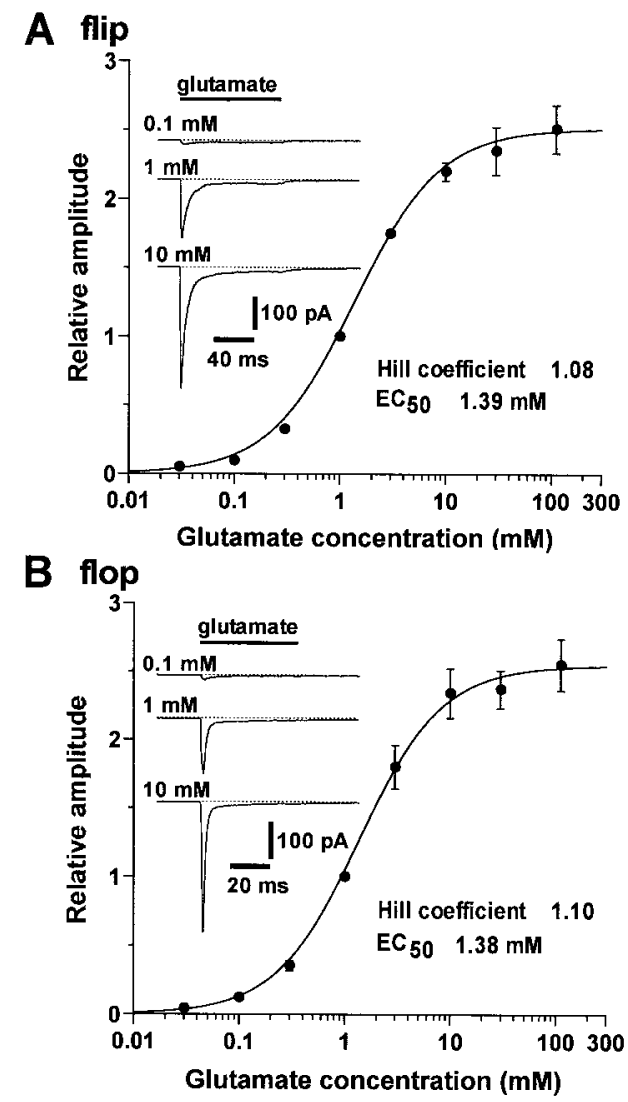

Figure 2. Dose-response relationships for responses of GluR2Q flip ( $A$ ) and flop $(B)$ AMPA receptor channels to glutamate. The relative peak amplitudes of the current activated by each glutamate concentration, with the amplitude to $1 \mathrm{~mm}$ glutamate as a reference, are plotted against the concentration of glutamate. Each circle and bar represent the mean \pm SEM of the relative amplitude of glutamate response obtained from five to 10 patches. Data were fitted to the equation $I=I_{\max } /\left[1+\left(\mathrm{EC}_{50} / C\right)^{\mathrm{n}}\right]$, where $I$ is the peak amplitude of glutamate response, $I_{\max }$ is the maximal response, and $C$ is the concentration of glutamate. $\mathrm{EC}_{50}$ is the concentration producing a half maximal response, and $n$ is the Hill coefficient. The Hill coefficients obtained by the best nonlinear least-squares fit were 1.08 (flip) and 1.10 (flop), and $\mathrm{EC}_{50}$ values were 1.39 (flip) and 1.38 (flop) $\mathrm{mM}$. Insets show current responses induced by 100 (flip) and 50 (flop) msec pulses of $0.1,1$, and $10 \mathrm{~mm}$ glutamate. Membrane potential was held at $-100 \mathrm{mV}$.

$90 \%$ of the peak and the steady state. The value was plotted against the concentration of glutamate (Fig. $3 A d, B d$ ). It declined gradually up to $1 \mathrm{~mm}$ and reached a steady value at $3 \mathrm{~mm}$. We performed the following experiments using $1 \mathrm{~mm}$ glutamate, because the peak concentration of glutamate in the synaptic cleft has been estimated to be $\sim 1 \mathrm{~mm}$ (Clements et al., 1992; Colquhoun et al., 1992).

Responses to pulses of $1 \mathrm{~mm}$ glutamate of brief ( $1 \mathrm{msec}$ ), intermediate $(10 \mathrm{msec})$, and long $(100 \mathrm{msec})$ durations are superimposed in Figure 4, $A$ and $B$. The time constants of the current decay to $100 \mathrm{msec}$ pulses, defined as the desensitization time constants, ranged from 4.00 to $8.59 \mathrm{msec}(5.89 \pm 0.17 \mathrm{msec}, n=$ $50)$ in flip and from 0.93 to $1.74 \mathrm{msec}(1.18 \pm 0.05 \mathrm{msec}, n=37)$ in flop (Fig. 4C). When the patch pipette contained $2 \mathrm{~mm}$ $\mathrm{Mg}_{2}$ ATP and $0.2 \mathrm{~mm} \mathrm{Na}_{3} \mathrm{GTP}$, they were $5.59 \pm 0.32 \mathrm{msec}(n=$ $5)$ in flip and $1.08 \pm 0.10 \mathrm{msec}(n=5)$ in flop. The results indicated that the presence of ATP and GTP in the internal solution caused no significant change in the time constant for 

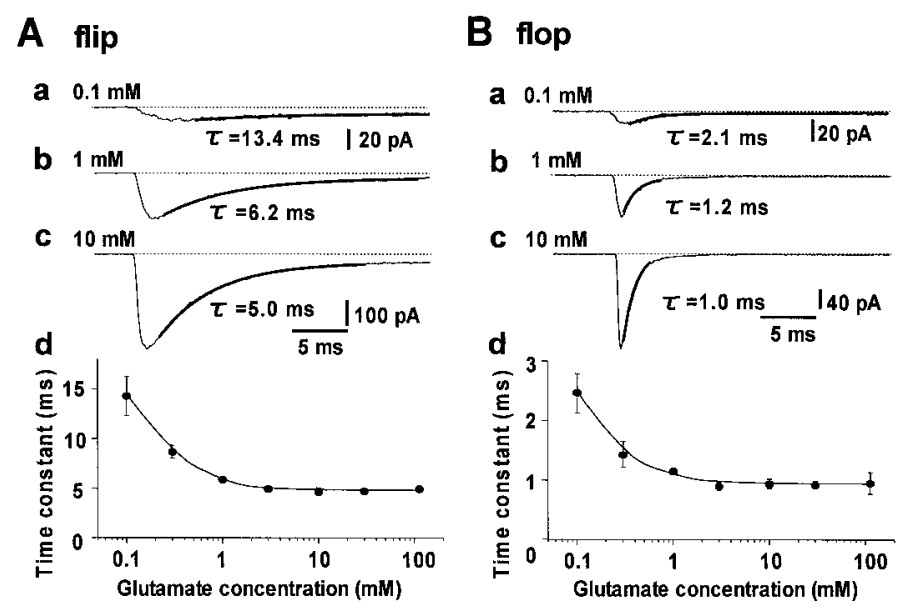

Figure 3. Dependence of desensitization time constant on agonist concentrations. $A, B$, Current responses to $0.1(a), 1(b)$, and $10(c) \mathrm{mm}$ glutamate in outside-out patches expressing GluR2Q flip $(A)$ and flop $(B)$ AMPA receptor channels. Each trace is the average of 10 responses (thin lines). The time constant for desensitization $(\tau)$ was obtained by fitting the decay of the current response with a single exponential function (thick lines). In the graphs in $d$, the means \pm SEM of the desensitization time constant were plotted against the concentration of glutamate. Data were pooled from four to 10 patches.

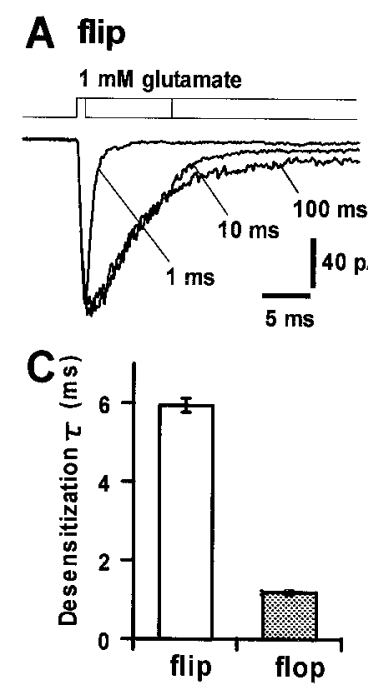

\section{B flop}

$1 \mathrm{mM}$ glutamate
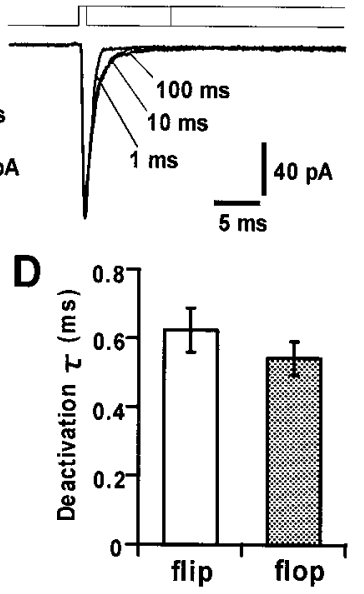

Figure 4. Kinetics of desensitization and deactivation in GluR2Q receptor channels. $A, B$, Superimposed current traces evoked by 1,10 , and 100 msec pulses of $1 \mathrm{~mm}$ glutamate in flip $(A)$ and flop $(B)$ variants. All traces are averages of 10 responses. The decay time constants of current responses after cessation of $1 \mathrm{msec}$ glutamate pulse and during $100 \mathrm{msec}$ pulse were defined as deactivation and desensitization time constants, respectively. Rectangular steps above traces indicate the duration of glutamate application. $C$, Comparison of desensitization time constants between flip (5.89 $\pm 0.17 \mathrm{msec}, n=50)$ and flop $(1.18 \pm 0.05 \mathrm{msec}, n=37)$ variants. $D$, Comparison of deactivation time constants between flip $(0.62 \pm 0.06 \mathrm{msec}, n=10)$ and flop $(0.54 \pm 0.05 \mathrm{msec}, n=10)$ variants. There was a significant difference in the desensitization time constant between flip and flop variants ( $p<0.001$, Student's $t$ test), whereas no differences were observed in the deactivation time constant $(p>0.3)$.

desensitization. Thus, the desensitization time constant during application of $1 \mathrm{~mm}$ glutamate in flip was approximately fivefold slower than that in flop in either experimental condition. In contrast, the decay time constants after $1 \mathrm{msec}$ pulses, tentatively designated as the deactivation time constants in this paper, were similar between the two splice variants. The values ranged from 0.33 to $0.80 \mathrm{msec}(0.62 \pm 0.06 \mathrm{msec}, n=10)$ in flip and from 0.41 to $0.70 \mathrm{msec}(0.54 \pm 0.05 \mathrm{msec}, n=10)$ in flop (Fig. $4 D)$, and there was no significant difference between these values. However, a possibility cannot be excluded that the difference would have been concealed by the solution exchange time inherent in the fast agonist application system.

Because the flop variant had fast desensitization kinetics, the current response to the intermediate duration $(10 \mathrm{msec})$ exhibited only a single decaying component, indicating that the channels desensitized almost completely within $10 \mathrm{msec}$. In contrast, there was a marked difference between the desensitization and deactivation kinetics in the flip variant. Therefore, the response induced by $10 \mathrm{msec}$ glutamate pulse exhibited two decaying components. It decayed slowly for the first $10 \mathrm{msec}$ with a time course for desensitization and decayed faster after removal of glutamate. However, the decay after cessation of $10 \mathrm{msec}$ pulse was slower than that observed after a $1 \mathrm{msec}$ pulse. To elaborate on this issue, we applied $1,5,10$, and $20 \mathrm{msec}$ pulses of $1 \mathrm{~mm}$ glutamate and compared the decay kinetics of the deactivation currents among them (Fig. $5 B$ ). In six patches tested, deactivation time constants were $0.52 \pm 0.07,0.80 \pm 0.10,1.37 \pm 0.20$, and $2.37 \pm$ $0.52 \mathrm{msec}$, respectively, after cessation of $1,5,10$, and $20 \mathrm{msec}$ pulses. Thus, the deactivation kinetics depended strongly on the extent of desensitization immediately before the removal of glutamate. The prolongation of the deactivation with increasing desensitization may be explained by assuming that the AMPAR in the desensitized state moves back to the undesensitized closed state via the open state. It has been shown that the time required for deactivation after removal of agonist increases in proportion to the extent of desensitization by a similar mechanism in $\mathrm{GABA}_{\mathrm{A}}$ receptor channels in cultured rat hippocampal neurons (Jones and Westbrook, 1995).

To provide a better quantitative description of the above finding, a kinetic model was investigated. We adopted a model proposed by Jonas et al. (1993), which could predict current responses of outside-out patches to fast applications of glutamate in CA3 pyramidal neurons. This model assumes fast desensitization upon agonist binding before and after opening of the channel (Fig. 5A). In this model, $C$ is the unliganded closed state, and $C A 1$ and $C A 2$ are single- and double-liganded closed states, respectively. $D 1, D 2$, and $D 3$ are desensitized closed states, $O A 2$ is a double-liganded open state, and $c$ indicates the concentration of glutamate. The set of rate constants shown in the legend of Figure 5 determined by a combination of trial and error and optimization accurately predicted the experimentally obtained current traces (Fig. $5 B)$. In this set of rate constants, $k 15\left(1.6 \times 10^{4}\right.$ $\left.\mathrm{sec}^{-1}\right)$ and $k 16\left(1.2 \times 10^{4} \mathrm{sec}^{-1}\right)$, the transition rate constants between $D 2$ and $D 3$, were more than two orders faster than $k 9$ $\left(1.0 \times 10^{2} \mathrm{sec}^{-1}\right)$ and $k 10\left(2.1 \mathrm{sec}^{-1}\right)$, those between $C A 2$ and $D 2$, and $k 11\left(3.0 \times 10^{2} \mathrm{sec}^{-1}\right)$ and $k 12\left(1.5 \times 10 \mathrm{sec}^{-1}\right)$, those between $O A 2$ and $D 3$. Furthermore, $k 12$ was approximately sevenfold faster than $k 10$. Upon cessation of the glutamate pulse, therefore, most of the channels in the desensitized states (D2 and D3) would move back to the liganded and then unliganded closed states via the open state, making the deactivation kinetics of the current response slower.

To assess the validity of the kinetic model shown in Figure $5 A$, we examined the agreement between measured and predicted values regarding concentration dependence of the peak currents. The values $\mathrm{k} 1-\mathrm{k} 16$ obtained in Figure $5 B$ predicted that the open probabilities at the peak of the current responses to $0.1,1$, and 10 

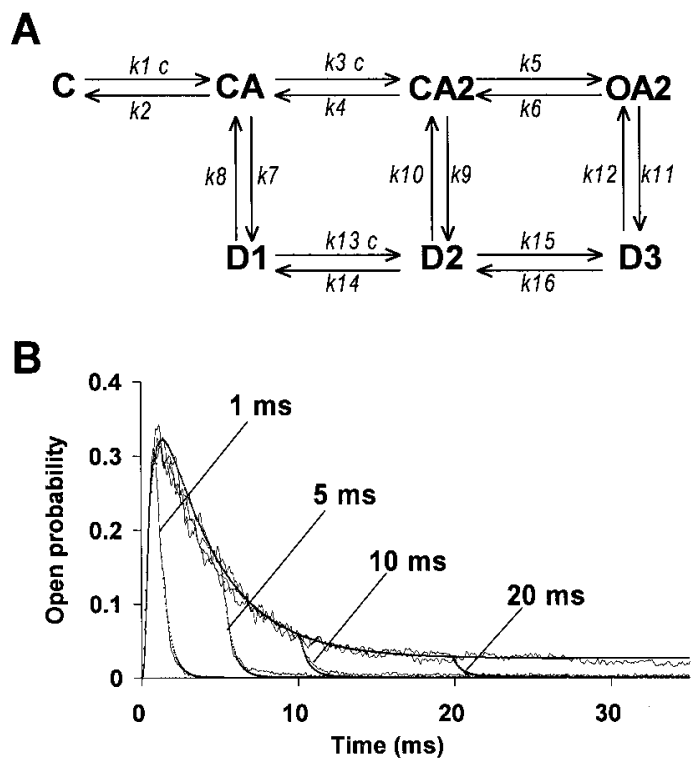

Figure 5. Glutamate-activated currents simulated by the kinetic model. $A$, Model used to describe kinetic reactions of GluR2Q flip AMPA receptor channels. The model assumes two binding sites for glutamate, three closed states, three desensitized states, and one open state. Thus, it has a total of seven states in which $C$ is the unliganded closed state, $C A$ is the single-liganded closed state, $C A 2$ is the double-liganded closed state, $O A 2$ is the double-liganded open state, $D 1$ is the single-liganded desensitized state, and $D 2$ and $D 3$ are double-liganded desensitized states. $c$ denotes glutamate concentration. The rate constants of the respective transitions were obtained by fitting to the actual current responses using a combination of trial and error with optimization. The kinetic responses were described satisfactorily with the following rate constant values: $k 1=$ $1.8 \times 10^{6} \mathrm{M}^{-1} \mathrm{sec}^{-1} ; k 2=2.4 \times 10^{3} \mathrm{sec}^{-1} ; k 3=1.0 \times 10^{7} \mathrm{M}^{-1} \mathrm{sec}^{-1}$; $k 4=1.0 \times 10^{4} \mathrm{sec}^{-1} ; k 5=1.6 \times 10^{4} \mathrm{sec}^{-1} ; k 6=5.0 \times 10^{3} \mathrm{sec}^{-1} ; k 7=$ $7.0 \times 10^{2} \mathrm{sec}^{-1} ; k 8=1.5 \times 10^{2} \mathrm{sec}^{-1} ; k 9=1.0 \times 10^{2} \mathrm{sec}^{-1} ; k 10=2.1$ $\mathrm{sec}^{-1} ; k 11=3.0 \times 10^{2} \mathrm{sec}^{-1} ; k 12=1.5 \times 10 \mathrm{sec}^{-1} ; k 13=1.0 \times 10^{7} \mathrm{M}^{-1}$ $\mathrm{sec}^{-1} ; k 14=1.0 \times 10^{3} \mathrm{sec}^{-1} ; k 15=1.6 \times 10^{4} \mathrm{sec}^{-1}$; and $k 16=1.2 \times$ $10^{4} \mathrm{sec}^{-1} . B$, Simulated responses calculated using the kinetic model with the values of transition rate constants described in $A$ (broken lines) were superimposed on actual current responses of GluR2Q flip AMPA receptor channels to $1,5,10$, and $20 \mathrm{msec}$ pulses of $1 \mathrm{mM}$ glutamate (thin continuous lines). The peak amplitude of $120 \mathrm{pA}$ obtained experimentally was adjusted to the maximum open probability of 0.32 in the simulated responses.

mu glutamate were $0.02,0.32$, and 0.68 , respectively. The corresponding values to 0.1 and $10 \mathrm{~mm}$ glutamate obtained experimentally in this patch were 0.01 and 0.66 when the value to $1 \mathrm{~mm}$ glutamate was set to 0.32 . We also estimated the open probabilities at the peaks of current responses to 1 and $10 \mathrm{~mm}$ glutamate using nonstationary fluctuation analysis (Sigworth, 1980). These values were $0.32 \pm 0.08(n=4)$ at $1 \mathrm{~mm}$ and $0.61 \pm 0.02(n=5)$ at $10 \mathrm{~mm}$. Thus, the model predicted the concentration dependence of the peak current reasonably.

\section{Recovery from desensitization}

A fraction of AMPARs becomes desensitized during brief exposure to $1 \mathrm{~mm}$ glutamate, although desensitization is not a major factor in determining the decay rate after cessation of the brief pulse (Colquhoun et al., 1992; Raman and Trussell, 1995). Significant desensitization of AMPAR is induced by synaptically released glutamate and regulates the strength of synaptic transmission to repetitive stimuli (Trussell et al., 1993; Otis et al., 1996). This regulation may depend at least partially on the functional diversities of postsynaptic AMPARs assembled from dif-

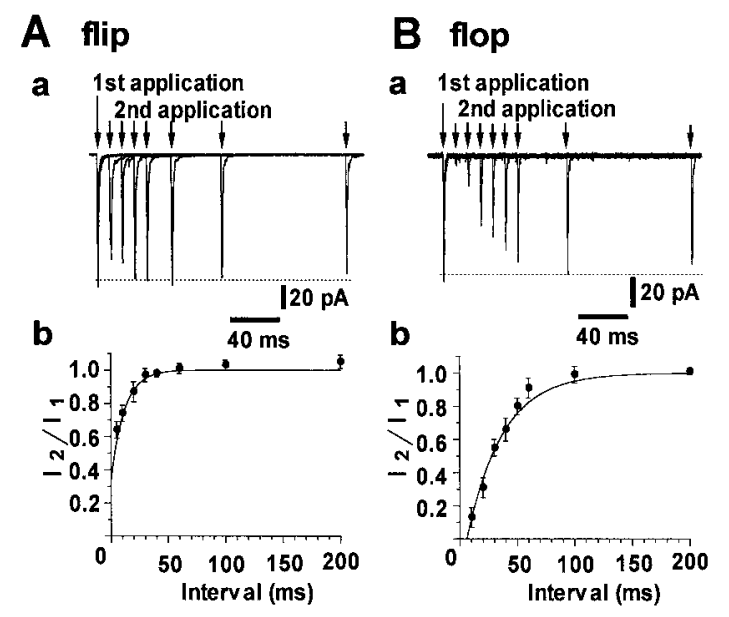

Figure 6. Recovery of GluR2Q flip $(A)$ and flop $(B)$ AMPA receptor channels from desensitization produced by a brief glutamate pulse. $a$, Superimposed current traces evoked by two $1 \mathrm{msec}$ pulses of $1 \mathrm{~mm}$ glutamate separated by different intervals. Each response to the second pulse is the average of three responses. $b$, Time course of recovery from desensitization. The amplitude of the second response relative to the first is plotted against the interval. Each circle and bar represent the mean \pm SEM of the relative amplitude of the second response obtained from six experiments in both flip and flop variants. The recovery time course was fitted with a single exponential function. The time constants for recovery were $11.7 \mathrm{msec}$ in flip and $31.3 \mathrm{msec}$ in flop. Membrane potential was held at $-100 \mathrm{mV}$.

ferent subunit compositions. To examine the extent of desensitization produced by a brief glutamate pulse and the time course of recovery from desensitization, we used a double-pulse protocol in which two successive $1 \mathrm{msec}$ pulses of $1 \mathrm{~mm}$ glutamate, separated by intervals of variable durations, were applied to the outside-out patches. Figure 6 shows that the response to the second pulse had a more substantial reduction in flop than in flip. The amplitude of the response to the second pulse given after a $10 \mathrm{msec}$ interval was reduced to $78 \pm 12 \%(n=10)$ and $12 \pm 2 \%(n=10)$ in the flip and flop variants, respectively. Furthermore, the time course of the recovery was extended for a more prolonged period in the flop variant. The average reduction of the response to the second pulse was plotted against the interval between the two pulses in flip and flop (Fig. $6 A b, B b$ ). The time course of the recovery could be fitted almost satisfactorily by a single exponential for both. The time constant was $11.7 \mathrm{msec}$ in flip and $31.3 \mathrm{msec}$ in flop.

\section{Effects of CTZ on kinetics of desensitization}

CTZ strongly potentiates AMPARs by reducing desensitization (Partin et al., 1993; Yamada and Tang, 1993). CTZ enhanced steady-state current responses to glutamate in homomeric GluR1, GluR3, and GluR4 and heteromeric GluR1/GluR2 AMPARs, and the extent of potentiation was more marked for AMPARs assembled from the flip form than from the flop form subunits (Partin et al., 1994, 1996). We examined the effects of CTZ on the GluR2Q AMPARs (Fig. 7).

CTZ at $100 \mu \mathrm{M}$ completely abolished desensitization caused by a $500 \mathrm{msec}$ pulse of $1 \mathrm{~mm}$ glutamate and increased the peak amplitude to $280 \pm 37 \%(n=5)$ of control in flip (Fig. $7 A)$. The response in flop was also enhanced by CTZ at $100 \mu \mathrm{M}$. However, the effect on flop was less efficient than that on flip. Namely, the peak amplitude was increased to $171 \pm 32 \%(n=5)$, and the response to $1 \mathrm{~mm}$ glutamate pulse showed substantial desensitization during the application period of $500 \mathrm{msec}$, although the 
A flip

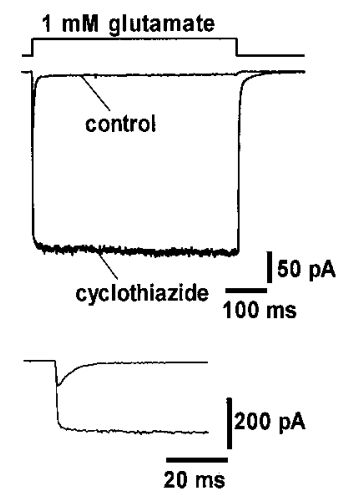

B flop
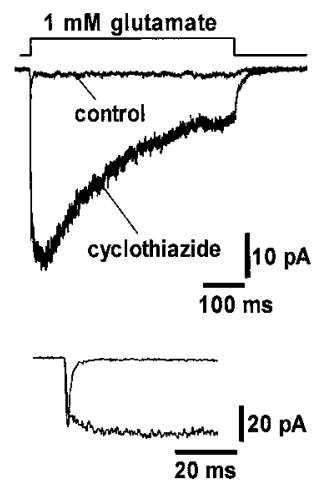

Figure 7. Effects of CTZ on responses to glutamate in GluR2Q flip ( $A$ ) and flop $(B)$ AMPA receptor channels. Current responses to $500 \mathrm{msec}$ pulses of $1 \mathrm{~mm}$ glutamate in the presence and absence of $100 \mu \mathrm{M} \mathrm{CTZ}$ are superimposed. Insets show the initial portion of the response with a faster sweep speed. When CTZ was applied, the control saline also contained $100 \mu \mathrm{M}$ CTZ. Membrane potential was held at $-100 \mathrm{mV}$.

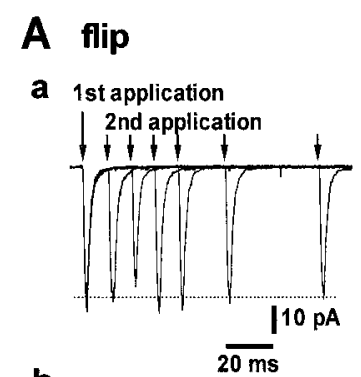

\section{B flop}

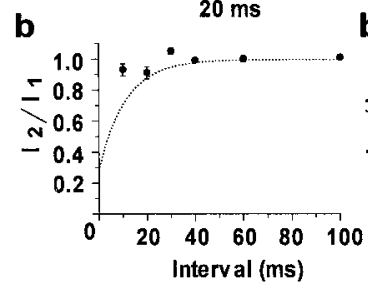

a 1 st application

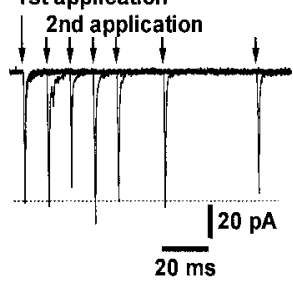

b

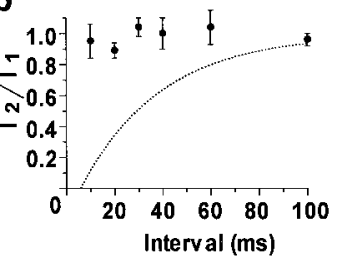

Figure 8. Recovery from desensitization of GluR2Q flip $(A)$ and flop $(B)$ AMPA receptor channels produced by a brief glutamate pulse in the presence of CTZ. $a$, Superimposed current traces evoked by two $1 \mathrm{msec}$ pulses of $1 \mathrm{~mm}$ glutamate separated by different intervals in the presence of $100 \mu \mathrm{M} \mathrm{CTZ}$. Each response to the second pulse is the average of three responses. $b$, Time course of recovery from desensitization. The amplitude of the second response relative to the first is plotted against the interval. Each circle and bar represent the mean \pm SEM of the relative amplitude of the second response obtained from four to six experiments. Broken lines indicate the time courses of recovery in the absence of CTZ, which are shown in Figure 6. Note that CTZ almost completely abolished the reduction of the second response in both flip and flop variants. Membrane potential was held at $-100 \mathrm{mV}$.

rate of desensitization was markedly reduced (Fig. $7 B$ ). Furthermore, it was noted that $\mathrm{CTZ}$ prolonged the rise time of the response to glutamate in flop (Fig. $7 B$, inset).

We next examined the effects of $100 \mu \mathrm{M} \mathrm{CTZ}$ on the desensitization produced by a brief $(1 \mathrm{msec})$ glutamate pulse. Figure 8 shows the responses to a double $1 \mathrm{msec}$ pulse of $1 \mathrm{~mm}$ glutamate separated by intervals of variable durations in the flip and flop variants. No substantial reduction in the response to the second pulse was detected in either variant, indicating that CTZ at 100 $\mu \mathrm{M}$ abolished the desensitization caused by a $1 \mathrm{msec}$ glutamate pulse. The result shown in Figure $7 B$ indicated that the desensi- tization during the $500 \mathrm{msec}$ glutamate pulse was not completely abolished by $100 \mu \mathrm{M} \mathrm{CTZ}$ in the flop variant. It is likely that in the presence of CTZ the desensitization process of the flop receptor is initiated so slowly that a brief glutamate pulse produces no substantial desensitization.

\section{Kinetic properties of heteromeric receptors assembled from edited and unedited forms of GluR2}

The recombinant AMPAR assembled from the GluR2R subunit, the edited form of GluR2, produces no appreciable current in response to glutamate when expressed in Xenopus oocytes (Boulter et al., 1990; Nakanishi et al., 1990; Herlitze et al., 1993). In this study, we examined the kinetic properties of homomeric GluR2 AMPARs by exploiting the fact that the recombinant AMPAR assembled from the GluR2Q subunit, the unedited form of GluR2, is capable of generating a current response sufficiently large for kinetic analysis in outside-out patch configurations. However, because only the edited form of GluR2 is expressed in the adult brain (Sommer et al., 1991; Burnashev et al., 1992), it is desirable to determine whether the kinetic properties of the homomeric GluR2Q AMPAR are similar to those of AMPAR assembled from GluR2R. To address this issue, we examined kinetic properties of the heteromeric receptors assembled from GluR2R and GluR2Q. To increase the probability of incorporation of GluR2R into the receptor, we injected cRNAs of GluR2R and GluR2Q at a ratio of 4:1 into oocytes. Heteromeric AMPARs possessing GluR2R have either a linear or outwardly rectifying $I-V$ relationship, whereas those assembled from GluR1, GluR2Q, GluR3, and/or GluR4 show strong inward rectification (Seeburg, 1993; Hollmann and Heinemann, 1994). Therefore, we verified the formation of heteromeric AMPARs by determining $I-V$ relationships of responses to glutamate in each outside-out patch. In most patches derived from oocytes into which cRNAs of GluR2R and GluR2Q had been injected at a ratio of $4: 1$, the $I-V$ relationship of the response to glutamate was either linear or outwardly rectifying with $100 \mu \mathrm{M}$ spermine in the patch pipette (see Materials and Methods). In a small number of patches, however, the $I-V$ curve displayed a tendency toward inward rectification, even under these conditions. Such patches were discarded from the experiment.

Figure $9 A$ shows examples of the $I-V$ relationships in heteromeric GluR2Qflip/GluR2Rflip ( $a$ ) and GluR2Qflop/GluR2Rflop (b) receptors, which exhibited outward rectification. Current responses to 1 and $100 \mathrm{msec}$ pulses of $1 \mathrm{~mm}$ glutamate were recorded in these patches (Fig. 9B). In the flip receptor, the desensitization and deactivation time constants were $6.40 \pm 0.50$ and $0.63 \pm 0.14 \mathrm{msec}(n=9)$, respectively. In the flop receptor, they were $1.00 \pm 0.07$ and $0.58 \pm 0.06 \mathrm{msec}(n=11)$, respectively. These values were similar to those obtained in the homomeric GluR2Q receptor in both flip and flop variants. Furthermore, the response in flip had an appreciable steady-state current, whereas it was almost negligible in flop. The ratio of the amplitude of the steady-state current measured immediately before cessation of the $100 \mathrm{msec}$ glutamate pulse to that of the peak current was $6.7 \pm 0.8 \%(n=9)$ in flip and $1.2 \pm 0.2 \%(n=11)$ in flop. These values were again similar to those obtained in the homomeric GluR2Q receptor in both flip and flop variants. These results indicated that both desensitization and deactivation properties in the GluR2Q receptor were unaffected by incorporation of GluR2R. 
A

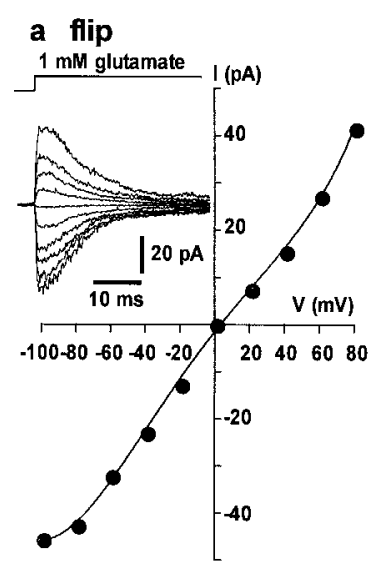

B

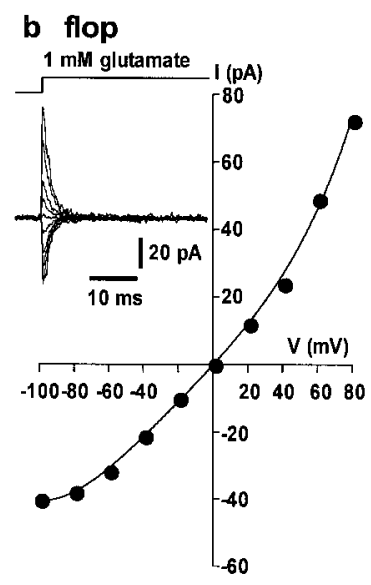

a flip
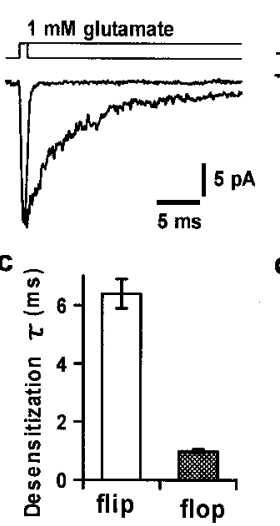

b flop

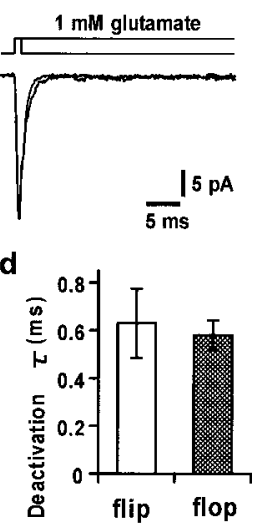

Figure 9. Current responses of heteromeric GluR2Q/GluR2R receptor channels. $A, I-V$ relationships of responses to glutamate obtained from outside-out patches excised from oocytes injected with the unedited (Q) and edited (R) forms of GluR2 cRNA at a ratio of 1:4. Both GluR2Q and GluR2R were of flip form in $a$ and of flop form in $b . I-V$ relationships were obtained by plotting the peak amplitudes of glutamate-induced currents against the membrane potential between -100 and $+80 \mathrm{mV}$ in $20 \mathrm{mV}$ steps. The current traces (average of 3 responses to $1 \mathrm{~mm}$ glutamate) at the different membrane potentials are superimposed in the insets. B, Kinetics of desensitization and deactivation in heteromeric GluR2Q/GluR2R (1:4) receptor channels. Current responses to brief $(1 \mathrm{msec})$ and long $(100 \mathrm{msec})$ glutamate pulses (average of 10 responses) are superimposed for flip in $a$ and for flop in $b$. Membrane potential was held at $-100 \mathrm{mV}$. $c$, Comparison of desensitization time constants between flip (6.40 $\pm 0.50 \mathrm{msec}, n=6)$ and flop $(1.00 \pm 0.07 \mathrm{msec}, n=6)$ variants. $d$, Comparison of deactivation time constants between flip $(0.63 \pm 0.14 \mathrm{msec}, n=5)$ and flop $(0.58$. \pm 0.06 msec, $n=6$ ) variants. There was a significant difference in the desensitization time constants between flip and flop variants ( $p<0.001$, Student's $t$ test), whereas no differences were observed in the deactivation time constants $(p>0.3)$.

\section{DISCUSSION}

One of the most striking features of the AMPAR is its extremely rapid and strong desensitization (Kiskin et al., 1986; Trussell and Fischbach, 1989; Mosbacher et al., 1994). The desensitization of postsynaptic AMPARs may have a profound effect on synaptic events. Because the kinetics and extent of desensitization differ markedly according to subunit composition of AMPARs, combining different AMPAR subunits may generate postsynaptic receptors finely tuned for encoding special signals in specific neuronal pathways (Trussell et al., 1994). To further clarify the molecular basis of desensitization of the AMPAR, we examined kinetic properties of the homomeric GluR2 AMPAR expressed in Xenopus oocytes using a fast agonist application technique. Differences in desensitization time constants between the flip and flop variants in homomeric GluR1, GluR3, and GluR4 receptors and heteromeric receptors assembled from one of them with GluR2R, the edited form of GluR2, have already been investigated (Mosbacher et al., 1994). However, the kinetic properties of the homomeric GluR2 receptor have not been examined, because no appreciable current response is detected when cRNA of GluR2R alone is injected into oocytes. In this study, we expressed the homomeric GluR2Q receptors in oocytes that produced a sufficiently large current in response to glutamate and examined the kinetic properties of the homomeric GluR2 receptors. We found that the time constant for desensitization during application of $1 \mathrm{~mm}$ glutamate in flip $(5.89 \mathrm{msec})$ was approximately fivefold slower than that in flop $(1.18 \mathrm{msec})$, whereas the deactivation time constants were similar. The most prominent difference in the desensitization time constant between flip and flop was reported in GluR4 in which the value during application of 1 $\mathrm{mm}$ glutamate in flip $(3.6 \mathrm{msec})$ was approximately fourfold slower than that in flop $(0.9 \mathrm{msec})$ (Mosbacher et al., 1994). Thus, the difference in the desensitization rate between flip and flop was the largest in the GluR2Q homomeric receptor. All experiments in this study were done at a holding potential of $-100 \mathrm{mV}$, whereas those by Mosbacher et al. (1994) were conducted at -40 $\mathrm{mV}$. However, this does not disturb comparison between their data with ours, because there was no voltage dependence in the desensitization kinetics between -40 and $-100 \mathrm{mV}$ in both GluR2Q flip and flop receptors (M. Koike, unpublished data).

We also found that there was an appreciable steady-state current during application of $1 \mathrm{~mm}$ glutamate in flip, whereas it was negligible in flop. The ratio between the steady-state current relative to the peak current in flip was sixfold to sevenfold greater than that in flop. Furthermore, the amplitude of the steady-state current induced by $1 \mathrm{~mm}$ glutamate was greater than that induced by $1 \mathrm{~mm}$ kainate in flip, whereas the opposite was true in flop. Using the conventional two-microelectrode voltage-clamp method for oocytes expressing GluR2Q flip, we have confirmed recently that the glutamate-induced steady-state current in wholecell recordings is greater than that induced by the same concentration of kainate at any concentration of the agonist between 100 $\mu \mathrm{M}$ and $10 \mathrm{~mm}$ (S. Tsukada, M. Koike, K. Tsuzuki, and S. Ozawa, unpublished observations). This is a unique property of the GluR2Q flip homomeric receptor, because the amplitude of the kainate-induced steady-state current was invariably greater than that induced by glutamate at the same concentrations in any homomeric or heteromeric recombinant AMPARs reported previously (Keinänen et al., 1990; Sommer et al., 1990; Partin et al., 1993).

Only GluR2R mRNA, the edited form of GluR2, is expressed in the adult brain, and extremely low levels of GluR2Q mRNA are present in the fetal brain (Sommer et al., 1991; Burnashev et al., 1992). Therefore, it is important to determine whether the kinetic properties of the GluR2 receptor are altered by the exchange of the single amino acid residue from arginine to glutamine at the $\mathrm{Q} / \mathrm{R}$ site. In this study, we found no differences in the desensitization or deactivation time constants nor in the 
amplitude of the steady-state current between the heteromeric GluR2Q/GluR2R receptor and the homomeric GluR2Q receptors in either flip or flop variants. It is likely that the flip-flop segment located extracellularly between M3 and M4 functions independently of the amino acid species at the $\mathrm{Q} / \mathrm{R}$ site, which lies on the $\mathrm{C}$ terminus of the M2 segment and is considered to lie close to the intracellular surface of the plasma membrane (Hollmann et al., 1994).

When the other GluR subunits are assembled with GluR2, the difference in the kinetic properties between flip and flop of GluR2, i.e., slow and incomplete desensitization in flip and fast and almost complete desensitization in flop, seems to be conferred upon resultant heteromeric AMPARs. Combinations of GluR1, GluR3, and GluR4 subunits, irrespective of flip and flop, with GluR2 flip reduced the desensitization rate of the recombinant heteromeric receptor (Mosbacher et al., 1994). In native neurons, a positive correlation was found between the desensitization time constant and the relative abundance of GluR2 flip mRNAs (Geiger et al., 1995). Furthermore, the steady-state current in response to glutamate was greater when GluR2 flip was coassembled with the other subunits than when GluR2 flop was used (Sommer et al., 1990). Among the neuron species tested, the desensitization time constant was the slowest and the steady-state current was the largest in hilar mossy cells in which the flip form is predominant among the GluR2 mRNAs expressed (Geiger et al., 1995). In contrast, the desensitization time constant was the fastest and the steady-state current was almost negligible in the medial nucleus of the trapezoid body relay neurons in which only flop forms of GluR1, GluR2, and GluR4 mRNAs are expressed (Geiger et al., 1995). In the latter neurons, the dominant expression of GluR4 flop mRNAs (55\% of the total mRNA of the GluR, whereas GluR2 flop mRNAs account for 24\%) has been considered to be mainly responsible for the fast and complete desensitization (Geiger et al., 1995). However, the fast desensitization kinetics cannot be explained in neocortical nonpyramidal neurons by their GluR4 flop content, because little GluR4 expression was detected in these cells. In these neurons, the flop form is predominant among GluR2 mRNAs, whereas the flip form is predominant in pyramidal neurons that display slower desensitization kinetics (Lambolez et al., 1996). This suggested that the splice variants of GluR2 are important molecular determinants of desensitization kinetics in heteromeric AMPARs in native neurons.

Although the desensitization time constant shows a positive correlation with the relative abundance of the GluR2 flip subunit (Geiger et al., 1995), an open question is why the desensitization of native AMPARs containing GluR2 flip abundantly is twofold or threefold slower than that estimated here in the recombinant GluR2 flip receptors. Geiger et al. (1995) have reported that the desensitization time constants of AMPARs in CA3 hippocampal pyramidal cells and hilar mossy cells, in which $>30 \%$ of the total GluR mRNA are GluR2 flip mRNA, are 15.2 and $16.3 \mathrm{msec}$, respectively. They have conducted fast application experiments using patch pipettes filled with the internal solution containing 2 mM ATP. In this study, we used the internal solution containing both 2 mM ATP and $0.2 \mathrm{~mm} \mathrm{GTP}$ in some experiments. However, the presence of both ATP and GTP caused no change in the desensitization time constant in the recombinant GluR2 flip receptors. The reason for extremely slow desensitization kinetics in native AMPARs in CNS neurons with a high relative abundance of GluR2 flip mRNA is presently unknown.

The agonist-binding core of the AMPAR is formed by peptide segments termed S1 and S2. S1 includes $\sim 150$ amino acid resi- dues $\mathrm{N}$ terminal to $\mathrm{M} 1$, and $\mathrm{S} 2$ comprises residues between M3 and M4 (Stern-Bach et al., 1994; Wo and Oswald, 1995; Armstrong et al., 1998). The flip-flop region is located downstream of S2, being in close proximity to the point at which the extracellular domain enters the membrane at M4. This region would play an important role in linking the signal of the conformational change induced by agonist binding to the membrane-embedded portion of the channel pore. In this study, the replacement of the flip sequence of GluR2 [motif TP- $(\mathrm{X})_{8}-\mathrm{S}-(\mathrm{Y})_{3}-\mathrm{V}-(\mathrm{Z})_{16}-\mathrm{AKDSG}$ ] with the flop sequence [motif NA- $(\mathrm{X})_{8}-\mathrm{N}-(\mathrm{Y})_{3}-\mathrm{L}-(\mathrm{Z})_{16}-\mathrm{SGGGD]}$ markedly accelerated the kinetics of desensitization of glutamateinduced current. It has been suggested that the three successive glycines in flop may confer flexibility on this region, and the functional difference between flip and flop may be attributable to a differential flexibility of this portion (Sutcliffe et al., 1996). In the GluR1 subunit, however, the desensitization time constant is similar between the flip (3.4 msec) and the flop (3.7 msec), although the flip and flop have the sequences KDSG and GGGD, respectively, in the $\mathrm{C}$ terminus of the flip-flop region (Sommer et al., 1990; Mosbacher et al., 1994). To clarify the molecular mechanisms underlying the differences in the kinetics of AMPARs between flip and flop, more detailed information concerning the relationship between the kinetic properties and the amino acid sequences in the flip-flop region is needed.

\section{REFERENCES}

Armstrong N, Sun Y, Chen G-Q, Gouaux E (1998) Structure of a glutamate receptor ligand-binding core in complex with kainate. Nature 395:913-917.

Bochet P, Audinat E, Lambolez B, Crépel F, Rossier J, Iino M, Tsuzuki K, Ozawa S (1994) Subunit composition at the single-cell level explains functional properties of a glutamate-gated channel. Neuron 12:383-388.

Boulter J, Hollmann M, O'Shea-Greenfield A, Hartley M, Deneris E, Maron C, Heinemann S (1990) Molecular cloning and functional expression of glutamate receptor subunit genes. Science 249:1033-1037.

Bowie D, Mayer M (1995) Inward rectification of both AMPA and kainate subtype glutamate receptors generated by polyamine-mediated ion channel block. Neuron 15:453-462.

Burnashev N, Monyer H, Seeburg PH, Sakmann B (1992) Divalent ion permeability of AMPA receptor channels is dominated by the edited form of a single subunit. Neuron 8:189-198.

Clements JD, Lester RAJ, Tong G, Jahr CE, Westbrook GL (1992) The time course of glutamate in the synaptic cleft. Science 258:1498-1501.

Colquhoun D, Jonas P, Sakmann B (1992) Action of brief pulses of glutamate on AMPA/kainate receptors in patches from different neurones of rat hippocampal slices. J Physiol (Lond) 458:261-287.

Donevan SD, Rogawski MA (1995) Intracellular polyamines mediate inward rectification of $\mathrm{Ca}^{2+}$-permeable AMPA receptors. Proc Natl Acad Sci USA 92:9298-9302.

Dudel J, Franke C, Hatt H (1990) Rapid activation, desensitization, and resensitization of synaptic channels of crayfish muscle after glutamate pulses. Biophys J 57:533-545.

Geiger JRP, Melcher T, Koh DS, Sakmann B, Seeburg P, Jonas P, Monyer H (1995) Relative abundance of subunit mRNAs determining gating and $\mathrm{Ca}^{2+}$ permeability of AMPA receptors in principal neurons and interneurons in rat CNS. Neuron 15:193-204.

Häusser M, Roth A (1997) Dendritic and somatic glutamate receptor channels in rat cerebellar Purkinje cells. J Physiol (Lond) 501:77-95.

Herlitze S, Raditsch M, Ruppersberg JP, Jahn W, Monyer H, Schoepfer R, Witzemann V (1993) Argiotoxin detects molecular differences in AMPA receptor channels. Neuron 10:1131-1140.

Hollmann M, Heinemann S (1994) Cloned glutamate receptors. Annu Rev Neurosci 17:31-108.

Hollmann M, O'Shea-Greenfield A, Rogers SW, Heinemann S (1989) Cloning by functional expression of a member of the glutamate receptor family. Nature 342:643-648.

Hollmann M, Hartley M, Heinemann S (1991) $\mathrm{Ca}^{2+}$ permeability of KA-AMPA-gated glutamate receptor channels depends on subunit composition. Science 252:851-853. 
Hollmann M, Maron C, Heinemann S (1994) N-Glycosilation site tagging suggests a three transmembrane domain topology for the glutamate receptor GluR1. Neuron 13:1331-1343.

Hume RI, Dingledine R, Heinemann S (1991) Identification of a site in glutamate receptor subunits that controls calcium permeability. Science 253:1028-1031.

Isa T, Ino M, Itazawa S, Ozawa S (1995) Spermine mediates inward rectification of calcium-permeable AMPA receptor channels. NeuroReport 6:2045-2048.

Jonas P, Major G, Sakmann B (1993) Quantal components of unitary EPSCs at the mossy fibre synapse on CA3 pyramidal cells of rat hippocampus. J Physiol (Lond) 472:615-663.

Jonas P, Racca C, Sakmann B, Seeburg PH, Monyer H (1994) Differences in $\mathrm{Ca}^{2+}$ permeability of AMPA-type glutamate receptor channels in neocortical neurons caused by differential GluR-B subunit expression. Neuron 12:1281-1289.

Jones MV, Westbrook GL (1995) Desensitized states prolong GABA $_{\mathrm{A}}$ channel responses to brief agonist pulses. Neuron 15:181-191.

Kamboj S, Swanson GT, Cull-Candy SG (1995) Intracellular spermine confers rectification on rat $\mathrm{Ca}^{2+}$-permeable AMPA and kainate receptors. J Physiol (Lond) 486:297-303.

Keinänen K, Wisden W, Sommer B, Werner P, Herb A, Verdoorn TA, Sakmann B, Seeburg PH (1990) A family of AMPA-selective glutamate receptors. Science 249:556-560.

Kiskin N, Kristhal O, Tsyndrenko A (1986) Excitatory amino acid receptors in hippocampal neurons: kainate fails to desensitize them. Neurosci Lett 63:225-230.

Koh DS, Burnashev N, Jonas P (1995) Block of native $\mathrm{Ca}^{2+}$-permeable AMPA receptors in rat brain by intracellular polyamines generates double rectification. J Physiol (Lond) 486:305-312.

Lambolez B, Ropert N, Perrais D, Rossier J, Hestrin S (1996) Correlation between kinetics and RNA splicing of $\alpha$-amino-3-hydroxy-5methyl-4-isoxazolepropionic acid receptors in neocortical neurons. Proc Natl Acad Sci USA 93:1797-1802.

Lomeli H, Mosbacher J, Melcher T, Höger T, Geiger JRP, Kuner T, Monyer H, Higuchi M, Bach A, Seeburg PH (1994) Control of kinetic properties of AMPA receptor channels by nuclear RNA editing. Science 266:1709-1713.

Monyer H, Seeburg PH, Wisden W (1991) Glutamate-operated channels: developmentally early and mature forms arise by alternative splicing. Neuron 6:799-810.

Mosbacher J, Schoepfer R, Monyer H, Burnashev N, Seeburg PH, Ruppersberg JP (1994) A molecular determinant for submillisecond desensitization in glutamate receptors. Science 266:1059-1061.

Nakanishi N, Shneider NA, Axel R (1990) A family of glutamate receptor genes: evidence for the formation of heteromultimeric receptors with distinct channel properties. Neuron 5:569-581.

Otis T, Zhang S, Trussell LO (1996) Direct measurement of AMPA receptor desensitization induced by glutamatergic synaptic transmission. J Neurosci 16:7496-7504.

Partin KM, Patneau DK, Winters CA, Mayer ML, Buonanno A (1993) Selective modulation of desensitization at AMPA versus kainate receptors by cyclothiazide and concanavalin A. Neuron 11:1069-1082.

Partin KM, Patneau DK, Mayer ML (1994) Cyclothiazide differentially modulates desensitization of $\alpha$-amino-3-hydroxy-5-methyl-4isoxazolepropionic acid receptor splice variants. Mol Pharmacol 46:129-138.

Partin KM, Fleck MW, Mayer ML (1996) AMPA receptor flip/flop mutants affecting deactivation, desensitization, and modulation by cyclothiazide, aniracetam, and thiocyanate. J Neurosci 16:6634-6647.

Raman IM, Trussell LO (1995) The mechanism of $\alpha$-amino-3-hydroxy5-isoxazolepropionate receptor desensitization after removal of glutamate. Biophys J 68:137-146.

Seeburg PH (1993) The molecular biology of mammalian glutamate receptor channels. Trends Neurosci 16:359-365.

Sigworth FJ (1980) The variance of sodium current fluctuations at the node of Ranvier. J Physiol (Lond) 307:97-129.

Sommer B, Keinänen K, Verdoorn TA, Wisden W, Burnashev N, Herb A, Köhler M, Takagi T, Sakmann B, Seeburg P (1990) Flip and flop: a cell-specific functional switch in glutamate-operated channels of the CNS. Science 249:1580-1585.

Sommer B, Köhler M, Sprengel R, Seeburg PH (1991) RNA editing in brain controls a determinant of ion flow in glutamate-gated channels. Cell 67:11-19.

Stern-Bach Y, Bettler B, Hartley M, Sheppard PO, O'Hara PJ, Heinemann SF (1994) Agonist selectivity of glutamate receptors is specified by two domains structurally related to bacterial amino acid-binding proteins. Neuron 13:1345-1357.

Sutcliffe MJ, Wo ZJ, Oswald RE (1996) Three-dimensional models of non-NMDA glutamate receptors. Biophys J 70:1575-1589.

Trussell LO, Fischbach GD (1989) glutamate receptor desensitization and its role in synaptic transmission. Neuron 3:209-218.

Trussell LO, Zhang S, Raman IM (1993) Desensitization of AMPA receptors upon multiquantal neurotransmitter release. Neuron 10:1185-1196.

Trussell LO, Raman IM, Zhang S (1994) AMPA receptors and rapid synaptic transmission. Semin Neurosci 6:71-79.

Verdoorn TA, Burnashev N, Monyer H, Seeburg PH, Sakmann B (1991) Structural determinants of ion flow through recombinant glutamate receptor channels. Science 252:1715-1718.

Wo ZG, Oswald RE (1995) Unraveling the modular design of glutamate-gated ion channels. Trends Neurosci 18:161-168.

Yamada KA, Tang C-M (1993) Benzothiadiazides inhibit rapid receptor desensitization and enhance glutamatergic synaptic currents. J Neurosci 13:3904-3915. 